\title{
Maize Starch Biphasic Pasting Curves
}

\author{
E. M. Nelles*, J. Dewar*, M. L. Bason† and J. R. N. Taylorł \\ * CSIR, Division of Food Science and Technology, P.O. Box 395, Pretoria 000 1, South Africa; \\ † Newport Scientific, Unit 1, 2 Apollo Street, Warriewood, NSW 2102, Australia; \\ $\ddagger$ University of Pretoria, Department of Food Science, Cereal Foods Research Unit, \\ Pretoria 0002, South Africa \\ Received 1 February 1999
}

\begin{abstract}
The pasting of commercial maize starches was found to be a biphasic phenomenon, exhibiting an expected first viscosity peak as well as an unexpected, relatively large second viscosity peak under specific cooking conditions when using a Rapid Visco Analyser (RVA). The second peak formed at long holding times (between 32 and $45 \mathrm{~min}$ ), holding temperatures within the range of 82 to $95{ }^{\circ} \mathrm{C}$, starch concentrations from 8 to $13 \%$ with a wide range of initial heating rates $\left(0.5-10^{\circ} \mathrm{C} / \mathrm{min}\right)$ and shear conditions $(150-500 \mathrm{rev} / \mathrm{min})$. The second pasting peak is attributed to the formation of complexes between amylose and low levels of lipid present in maize starch. When lipid was partially removed by extraction with methanol-chloroform $(1: 3 \mathrm{v} / \mathrm{v})$, the second pasting peak disappeared. When, however, the starch sample was treated with solvent and the solvent removed by evaporation, the second peak remained, but formed earlier. Increasing the holding temperature gave a slightly higher first viscosity peak, slightly earlier, and led to a decrease in the area and height of the second viscosity peak. Increasing heating rate also led to an earlier, slightly higher first peak and earlier but lower second viscosity peak. Increasing starch concentration led to an increase in height and area of both the first and second peaks and their later occurrence. Increasing shear led to a decrease in height and area of both the first and second peaks and their later appearance.

(c) 2000 Academic Press
\end{abstract}

Keywords: Rapid Visco Analyser, pasting, maize starch, lipid-amylose complex.

\section{INTRODUCTION}

Cooking of starch is a unit operation in many food and other industrial manufacturing processes. The objectives of starch cooking (gelatinisation) include improvement of palatability and sensory appeal of starchy food products, alteration of the physical and/or chemical functionality of the starch and production of enzyme-susceptible starch. These products may contribute directly to human nu-

\footnotetext{
ABbReViations used: RVA= Rapid Visco Analyser.

Corresponding author: E. M. Nelles. Tel: 2712841 2221; Fax: 2712841 2386; E-mail: enelles@csir.co.za
}

tritional status or be utilised as relatively low cost, bulk nutrient and energy sources in industrial processes $^{1}$ such as beer brewing or syrup production.

Gelatinisation generally refers to the disruption of molecular order within starch granules, when they are heated above the gelatinisation temperature in the presence of sufficient water ${ }^{2}$ (at least 14 water molecules to one anhydrous glucose unit $^{3,4}$ or enough water so that its addition does not lower the temperature of gelatinisation $\left.{ }^{3,5}\right)$. Evidence for the loss of molecular order includes: irreversible granule swelling, loss of birefringence, loss of crystallinity, viscosity development and starch solubilisation ${ }^{2,6}$. Pasting is the phenomenon 
following gelatinisation in the dissolution of starch $^{6}$. It involves granular swelling, exudation of molecular components from the granule, and eventually total disruption of the granules. To some degree, the terms gelatinisation and pasting are interchangeable. Gelatinisation, however, refers specifically to the disruption of molecular order of the starch polymers and occurs first, whilst pasting refers more to the evidence of the disruption of molecular order such as viscosity development (i.e. increase in the viscosity of the starch paste).

Heating of starch in excess water results in 'melting' of starch granules, with loss of X-ray crystallinity ${ }^{7}$. Almost simultaneously, a loss of birefringence can be observed. At the same time, the starch granules may swell to many times their original size, depending on spatial constraints. The swelling of granules and the melting of crystallites are semi-co-operative processes ${ }^{8}$. These changes in the structure of the starch granules are accompanied by the separation of amylose and amylopectin, and results in leaching of amylose from the granules. A combination of granule swelling and solubilisation results in a very high increase in viscosity ${ }^{9}$. If shear is applied at this stage, granules are disrupted and a paste is formed ${ }^{2}$. Without shear, the granule is not completely solubilised until a temperature in excess of $120^{\circ} \mathrm{C}$ is reached ${ }^{10}$. A starch paste is a viscous mass consisting of a continuous phase (a molecular dispersion) of solubilised amylose and/or amylopectin and a discontinuous phase of granule remnants (granule ghosts and fragments).

Changes in viscosity of starch pastes can be followed by viscograph-type instruments such as the Rapid Visco Analyser (RVA). The RVA is a heating and cooling viscometer configured especially for testing starch-based and other products requiring precise control of temperature and shear ${ }^{11}$. It is claimed to measure changes in viscosity of a system over time as the system is stirred during heating and cooling, according to pre-set temperature and shear profiles. In accordance with other usage in literature ${ }^{12-15}$, the term viscosity is used. A typical RVA testing profile for starch involves heating the starch slurry from 50 to $95^{\circ} \mathrm{C}$ within 4-8 min, holding it at $95^{\circ} \mathrm{C}$ for $2-5 \mathrm{~min}$ before cooling it to $50^{\circ} \mathrm{C}$, with a total test-time of 13 to $23 \mathrm{~min}^{16}$. Typical shear input would be a rapid $(10 \mathrm{~s})$ stir at $960 \mathrm{rev} / \mathrm{min}$ followed by stirring at $160 \mathrm{rev} / \mathrm{min}$ during the heating and cooling cycles. Typically the resulting pasting curve for maize starch shows a rapid increase in viscosity due to granule swelling and starch leaching ${ }^{2}$, with a peak in viscosity above the starch gelatinisation temperature. This is typically followed by a decline in viscosity (viscosity breakdown) due to soluble starch molecules orienting themselves in the direction that the system is being stirred ${ }^{10}$ and the break up of starch granules ${ }^{2}$. Finally, viscosity increases due to a decrease of energy in the system and subsequent hydrogen bond formation between starch chains (setback) ${ }^{10}$ when the starch product is cooled ${ }^{3}$. Comparisons between the RVA, Brabender Visco/Amylo/graph and other viscometers commonly used, have shown that although the mechanics of these instruments differ, comparable results are achieved ${ }^{15,17}$. Although in a comparative study, it was reported that due to the versatility of the RVA, it may sometimes be better suited to measurements of starch properties than other instruments ${ }^{15}$.

This paper describes a biphasic pasting curve for commercial maize starch, observed when it is cooked in a RVA instrument using parameters to simulate some industrial starch cooking processes carried out at high altitude $(1500 \mathrm{~m})$ in South Africa a heating rate of approximately $4{ }^{\circ} \mathrm{C} / \mathrm{min}$, a holding period of $90 \mathrm{~min}$, a holding temperature of $90^{\circ} \mathrm{C}$, a shear input of $160 \mathrm{rev} / \mathrm{min}$ and a starch concentration of $13 \%$ ) and the effect of various parameters (temperature, heating rate, concentration and shear) on the nature of the curve.

\section{EXPERIMENTAL}

\section{RVA pasting curves}

\section{Standard RVA profile}

A Rapid Visco Analyser (RVA) (Newport Scientific, Warriewood, Australia) was used to measure the apparent viscosity of samples as a function of temperature, time and stirring. Suspensions $(13 \% \mathrm{w} / \mathrm{w}$ dry mass basis) of commercial native maize starches: BDH (cat. 302617 H), Saarchem (cat. 5871400), Maizena $^{\circledR}$ (Robertsons, South Africa) and Cal starch (Starch Australasia cat. $3401 \mathrm{c}$ ) were each freshly prepared and loaded in a Series 3 D RVA utilising Thermocline for Windows Version 1.1. The starch suspension was stirred rapidly at $900 \mathrm{rev} / \mathrm{min}$ for $10 \mathrm{~s}$ before the shear input was decreased and held constant at $160 \mathrm{rev} / \mathrm{min}$ for the heating and cooling cycles. The suspension was heated from $50-90^{\circ} \mathrm{C}$ in $10 \mathrm{~min}$, then held at $90^{\circ} \mathrm{C}$ 
for $90 \mathrm{~min}$ before cooling to $65^{\circ} \mathrm{C}$ over $10 \mathrm{~min}$. All pasting curves were performed at least in duplicate. The viscosity was expressed in $\mathrm{cP}$.

Factors influencing the dissolution of starch granules including shear, starch concentration, temperature and heating rate $^{2,10}$ were investigated with reference to the above pasting profile.

\section{Effect of temperature}

Slurries of regular maize starch (Staley Pure Food Powder, U.S.A.) (13\% w/v dry mass basis), were prepared and pasting curves were produced with a Series 4 (in Australia) RVA utilising Thermocline for Windows Version 2.0 software, using the standard $160 \mathrm{rev} / \mathrm{min}$ shear input and adapting the profiles to raise the temperature from $50^{\circ} \mathrm{C}$ to $(\mathrm{a})$ $80^{\circ} \mathrm{C}$, (b) $82^{\circ} \mathrm{C}$, (c) $85^{\circ} \mathrm{C}$, (d) $88^{\circ} \mathrm{C}$, (e) $90^{\circ} \mathrm{C}$, (f) $92^{\circ} \mathrm{C}$, (g) $95^{\circ} \mathrm{C}$ and $(\mathrm{h}) 98^{\circ} \mathrm{C}$ in $10 \mathrm{~min}$, followed by holding the respective samples as these temperatures for $90 \mathrm{~min}$ before cooling to $65^{\circ} \mathrm{C}$.

\section{Effect of heating rate}

$\mathrm{BDH}$ starch suspensions of $13 \%$ (w/w dry mass basis), were prepared and pasting curves were produced using the standard profile shear input and a temperature of $90^{\circ} \mathrm{C}$ but altering the heating rate (from $60{ }^{\circ} \mathrm{C}$ to $90^{\circ} \mathrm{C}$ ) to (a) $0.5^{\circ} \mathrm{C} / \mathrm{min}$, (b) $1{ }^{\circ} \mathrm{C} / \mathrm{min}$, (c) $3{ }^{\circ} \mathrm{C} / \mathrm{min}$ and (d) $10^{\circ} \mathrm{C} / \mathrm{min}$ before holding the sample at $90^{\circ} \mathrm{C}$ for $60 \mathrm{~min}$ and cooling to $65^{\circ} \mathrm{C}$ in $10 \mathrm{~min}$.

\section{Effect of concentration}

$\mathrm{BDH}$ starch suspensions were prepared at different concentrations $(8 \%, 9 \cdot 25 \%, 11 \%$ and $13 \% \mathrm{w} / \mathrm{w}$ dry mass basis), and pasting curves produced using the standard temperature, time and stirring profile.

\section{Effect of shear input}

BDH starch suspensions of 13\% (w/w dry mass basis), were prepared and pasting curves produced with the RVA using the standard temperature and time profile but increasing the constant shear input $(160,200,300,500 \mathrm{rev} / \mathrm{min})$ during the heating and cooling cycles.

\section{Defatting of starch sample}

Starch (20 g) was mixed with $150 \mathrm{~mL}$ chloroformmethanol $(2: 1 \mathrm{v} / \mathrm{v})$ and placed in a shaking waterbath at $30^{\circ} \mathrm{C}$ for $180 \mathrm{~min}$. The solvent was then decanted or evaporated in a convection drying oven at $50^{\circ} \mathrm{C}$. The extracted starch was dried in a convection drying oven at $50{ }^{\circ} \mathrm{C}$ for $30 \mathrm{~min}$.

\section{Analysis}

\section{Lipid}

Starch lipid content was determined gravimetrically after bound lipids had been released by hydrochloric acid hydrolysis and extracted with petroleum ether ${ }^{18}$.

\section{Phospholipid}

For phospholipid determination, starch samples were ashed overnight at $520^{\circ} \mathrm{C}$ in a muffle furnace. The ashed samples were treated with $2 \mathrm{~mL}$ concentrated $\mathrm{HNO}_{3}$ and dried for $1 \mathrm{~h}$ at $520^{\circ} \mathrm{C}$. The samples were then dissolved in $2 \mathrm{~mL}$ concentrated HCl, filtered through a Whatman No. 541 paper and made up to $25 \mathrm{~mL}$ with distilled water. Phosphorus was measured with an inductively coupled plasma-optical emission spectrometer (Leeman ICP, U.S.A.) at a wavelength of $213.618 \mathrm{~nm}$ against a potassium di-hydrogen phosphate standard. Phospholipid was calculated by multiplying the phosphorus content by $16 \cdot 3^{19}$.

\section{Amylose/amylopectin ratio}

An amylose/amylopectin assay kit (Megazyme International Ireland, Wicklow, Ireland) was used to determine the amylose/amylopectin ratios of maize starches. This assay is based on the principle of specific formation of amylopectin complexes with the Concanavalin A, after a pre-treatment to remove lipids.

\section{RESULTS AND DISCUSSION}

All the maize starches, as expected, gave a steep rise in viscosity from about $68^{\circ} \mathrm{C}$ and gave a first viscosity peak at approximately $10 \mathrm{~min}$, followed by a decrease in viscosity (Fig. 1). Unexpectedly they then gave a large second viscosity peak (height in $\mathrm{cP} \sim 80 \%$ of first peak, and area in cP.min $\sim 200 \%$ of first peak) at approximately 32-45 min (which is a longer period than a normal RVA pasting curve) followed by a second decrease in viscosity before set-back during cooling. All maize starches gave similar pasting curves but differed slightly in terms of pasting peak times and heights and breakdown viscosity troughs.

The double pasting peak phenomenon was also observed with a Brabender Viscograph model E 


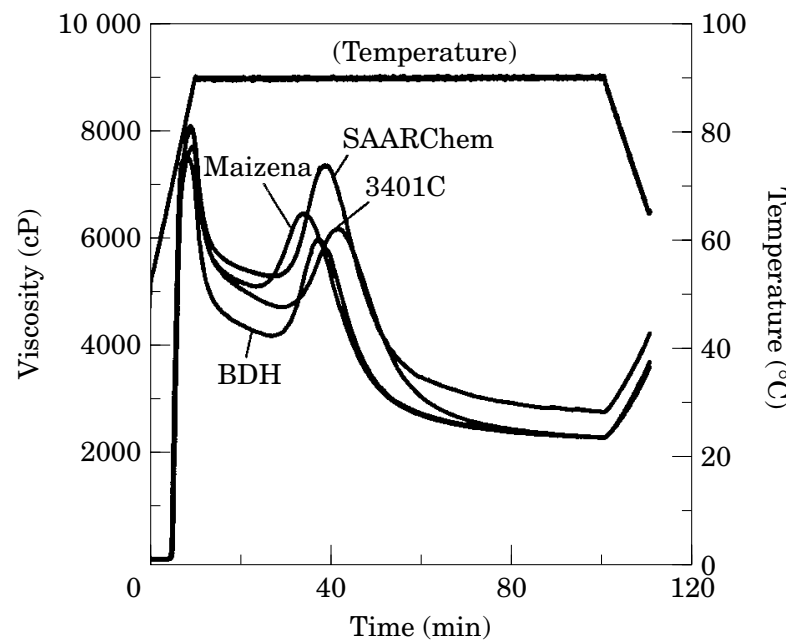

Figure 1 Pasting curves of different native maize starches.

instrument (data not shown) with its calibration maize starch under similar conditions: heating rate $3.0{ }^{\circ} \mathrm{C} / \mathrm{min}$; holding time $90 \mathrm{~min}$; holding temperature $90^{\circ} \mathrm{C}$; starch concentration $13 \%$ and speed, $150 \mathrm{rev} / \mathrm{min}$.

This is the first time a second pasting viscosity peak has been observed during the holding part (constant cooking temperature) of a pasting curve when maize starch is subjected to a pasting program in a Visco/Amylograph-type instrument. This double peak has probably not been observed previously because of the relatively long holding time $(<45 \mathrm{~min})$ which are not normally used in pasting investigations. However, a two stage change in paste viscosity was identified previously during the heating part of a pasting curve with a Brabender viscograph when wheat and maize starch was cooked in the presence of $1 \%$ carboxymethyl cellulose ${ }^{20}$. A small 'bump' in the viscosity curve has been observed occasionally in the setback phase or the re-cooking of wheat derivatives in both the Brabender Visco/Amylo$\operatorname{graph}^{21,22}$ and the $\mathrm{RVA}^{23}$. This has been attributed to complexing of the solubilised starch with polar lipids. A second peak has also been reported in the cooling part of the pasting curve using a Brabender Viscograph when wheat and maize starch had been impregnated with lipids ${ }^{20}$.

When the commercial maize starches were defatted with chloroform-methanol the second viscosity peak virtually disappeared. Figure 2 shows

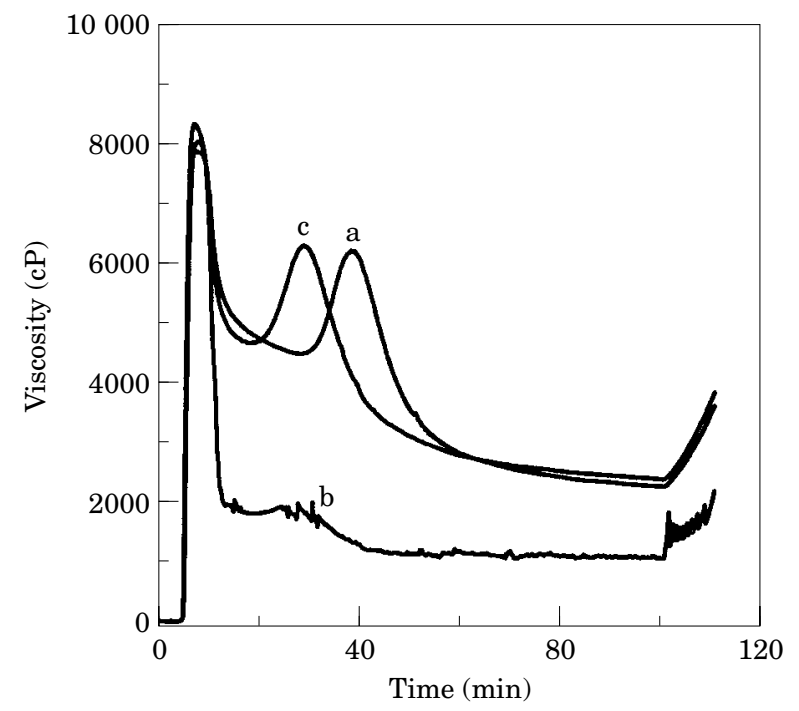

Figure 2 Effect of defatting on $\mathrm{BDH}$ maize starch pasting curves. (a) control; (b) defatted, fat removed; (c) defatted, fat added back.

that the expected first peak in viscosity is followed by a steep decline in viscosity due to viscosity breakdown, slight indications of an earlier than expected second peak and an increase in viscosity due to set-back when the starch was cooled ${ }^{3}$. The pasting curve of the defatted sample was irregular, probably due to the extraction of fat which also acts as plasticiser. The same general pattern was followed by other commercial maize starches treated in this way (data not shown). When the starch was treated with solvent and the solvent removed by evaporation (sample c), the second peak remained, but formed approximately $8 \mathrm{~min}$ earlier than for unextracted starch. The same tendency to form a second peak but at an earlier time occurred with the other commercial maize starches treated in this way (data not shown). The fact that the peak remained in the 'extracted-withfat' sample c, indicates that a fraction removable by solvent extraction, i.e. lipid, is involved in the formation of the second pasting peak. Extraction probably freed the lipid to some degree from the granules, allowing the lipid greater freedom of movement, so that complexes formed earlier. Previously, when a two stage change in paste viscosity was observed with a Brabender Viscograph during the heating part of the pasting curve ${ }^{20}$, removal of lipids eliminated the second stage pasting peak, reduced consistency and setback and decreased the pasting temperature by approximately $4{ }^{\circ} \mathrm{C}$ for maize starch. It has been reported that defatting 
Table I Lipid contents and amylose/amylopectin ratios of commercial maize starches

\begin{tabular}{lcc}
\hline $\begin{array}{l}\text { Maize starch } \\
\text { sample }\end{array}$ & $\begin{array}{c}\text { Lipid content } \\
(\% \text { dry starch) }\end{array}$ & $\begin{array}{c}\text { Amylose } \\
(\% \text { dry starch })\end{array}$ \\
\hline BDH & $0 \cdot 6 \pm 0 \cdot 0^{a}$ & $29 \pm 0 \cdot 5^{a}$ \\
Saarchem $^{\circledR}$ & $0 \cdot 6 \pm 0 \cdot 0$ & $27 \pm 0 \cdot 7$ \\
Maizena $^{\circledR}$ & $0 \cdot 8 \pm 0 \cdot 1$ & $27 \pm 0 \cdot 9$ \\
Cal starch $^{\text {al }}$ & $0 \cdot 7 \pm 0 \cdot 1$ & $26 \pm 0 \cdot 3$ \\
\hline
\end{tabular}

${ }^{a}$ Standard deviation of the mean; $n=2$.

of starch results in a decrease in gelatinisation temperature and often in an increase in (first) peak viscosity as measured by an amylograph ${ }^{24-27}$. Some conflicting results, where defatting of starch did not result in a decrease in gelatinisation temperature, have been explained by incomplete lipid removal and further complexing of lipid and starch during the extraction process ${ }^{20}$. The results shown in Figure 2 provide no clear evidence of a decrease in the gelatinisation temperature of the defatted sample but it is possible that the relatively high heating rate $\left(\sim 4^{\circ} \mathrm{C} / \mathrm{min}\right)$ in the standard temperature profile used, prevented identification of such a difference. Reduced consistency and reduced setback in the pasting curve of the defatted sample are, however, evident and in agreement with literature ${ }^{20}$.

The phosphorus content of starch gives an indication of its phospholipid content which in turn gives an indication of one form of lipid complexed with amylose ${ }^{19}$. Solvent extraction with removal of the solvent decreased the phospholipid content of the maize starches from $0 \cdot 26 \%$ to $0 \cdot 18 \%$ (i.e. by approximately 30\%) whereas the extraction without solvent removal did not reduce the phosphorus content, suggesting that phospholipid is at least partly responsible for the second viscosity peak. It is suggested that complexes of amylose with free fatty acids ${ }^{19}$, monoacyl lipids ${ }^{19}$ and perhaps even diglycerides ${ }^{28}$ may also contribute to the second pasting peak phenomenon.

Even low levels of monoacyl lipids $(0 \cdot 1 \%$, based on starch) affect the pasting and gelling properties of $\operatorname{starch}^{29,30}$. Starch granules have intrinsic free fatty acids and lysophospholipids, in amounts directly related to amylose content, distributed asymmetrically throughout the granule ${ }^{31}$. Amylose/ amylopectin ratios and percentage lipid present in the commercial maize starches used in the experiments are given in Table I. These are consistent with values reported for maize $\operatorname{starch}^{10}$ and indicate that sufficient lipid was present in the commercial starches to form amylose-lipid complexes and affect the pasting properties of these starches. Proof that amylose-lipid inclusion complexes do exist in native starch granules and that they are not artefacts formed during starch isolation has been obtained using ${ }^{13} \mathrm{C}$-crosspolarisation/magic-angle spinning nuclear magnetic resonance supplemented with other evidence $^{32-34}$. Inclusion complexes, however, form readily with added lipid as well ${ }^{19,28}$.

Amylose complexes with most lipids are insoluble and amorphous (Type I), but they can be annealed into a semi-crystalline form (Type II $)^{19}$. Type I complexes, which are probably present in most cereal starches, generally dissociate on heating in water at $94-100^{\circ} \mathrm{C}^{36,37}$ as shown by $\mathrm{X}$-ray diffraction. Type II complexes, originally found in starches after gelatinisation ${ }^{38}$, dissociate at $100-125^{\circ} \mathrm{C}^{35,36}$. Only Type II complexes give strong wide-angle X-ray diffraction patterns ${ }^{36}$. It is suggested that the second viscosity peak is in fact due to the formation, followed by the dissociation, of the Type II complex since they are known to form after gelatinisation ${ }^{35,37}$ as is the case of the second pasting peak. It is further proposed that added shear during heating, as with the RVA instrument, lowers the temperature needed for the dissociation of the Type II complex (as is indeed the case with granular disruption to form a starch paste $^{10}$ ) and prevents the complex from surviving for a longer period. Thereby, a relatively sharp second pasting peak, representing viscosity development due to complexing and viscosity breakdown due to the dissociation of complexes, is created. It is suggested that complexing of amylose with lipid results in the formation of structures with greater potential for entanglement.

Since this double peak phenomenon during the constant temperature part of the pasting curve is novel, the effects of temperature, heating rate, concentration and shear on the pasting profile of maize starch were investigated. These parameters are of particular importance in starch cooking processes.

Figure 3 shows the effect of different holding temperatures on the pasting curve. At $80{ }^{\circ} \mathrm{C}$ there was only a slight reduction in viscosity during the holding period. No clear first or second peaks were distinguishable. In fact, the viscosity increased gradually throughout the holding period. It would seem that the thermal energy input was insufficient to give a clear gelatinisation viscosity peak. Al- 


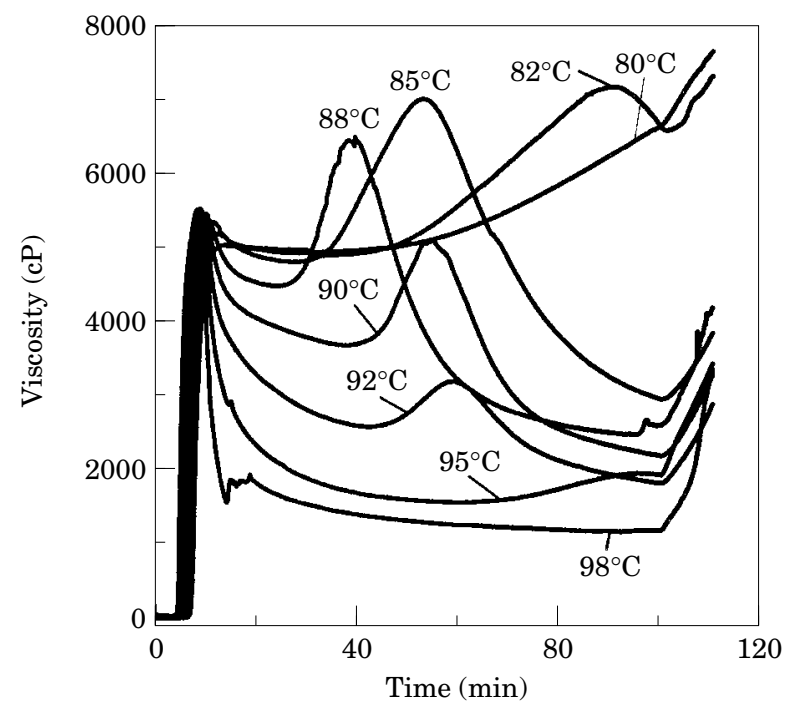

Figure 3 Pasting curves of Staley Pure Food Powder maize starch produced with different holding temperatures.

though sufficient energy was given to reach a peak viscosity of $\sim 5000 \mathrm{cP}$, very limited viscosity breakdown took place (a decrease in viscosity of only $109 \mathrm{cP}$ was measured). Heating to 82,85 and $88^{\circ} \mathrm{C}$ produced both clearly distinguishable first and second peaks. These areas of the second peak were larger than the first viscosity peaks, with the second viscosity peak areas becoming progressively smaller and occurring earlier as the temperature of the cooking increased. Heating starch to 90,92 and $95^{\circ} \mathrm{C}$ again produced both clearly distinguishable first and second peaks. The areas of the second peak were smaller than the first peak areas, with the second peak areas becoming progressively smaller and occurring later as the temperature of cooking increased. Heating starch at $98{ }^{\circ} \mathrm{C}$ produced only a first peak during the $90 \mathrm{~min}$ cooking period. It is possible that a second peak could have occurred with more prolonged holding at this temperature, but this is unlikely as the second peaks became progressively smaller with increase in temperature. Although not apparent from Figure 3, but clear from analysis of the peaks heights and times of occurrence, the first peaks were reached sooner, and became progressively higher, with each increase in temperature. This may be attributed to the greater thermal energy input in a given time due to a higher temperature and heating rate. Inspection of Figure 3 and analysis of the data also shows that an increase in thermal energy input led to a decrease in area and height of the second viscosity peaks. This is

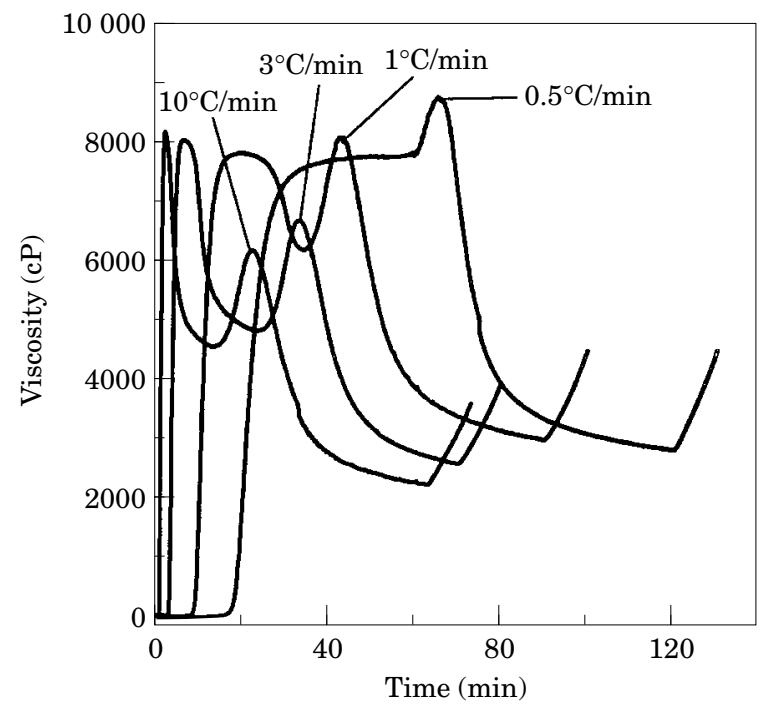

Figure 4 Pasting curves of $\mathrm{BDH}$ maize starch produced with different heating rates.

probably due to a decrease in the time for the formation of amylose-lipid complex II before sufficient energy is applied to dissociate complex II. The size and time of appearance of the second viscosity peaks is more sensitive to pasting temperature than the first viscosity peak; this suggests that the mechanisms involved with the forming of the two peaks are different.

Figure 4 shows the effect of heating at different rates to constant holding temperature $\left(90^{\circ} \mathrm{C}\right)$ on the pasting curve. The time taken to produce the first peak decreased as the heating rate increased. Peak 1 viscosity and the temperature at which peak 1 maximum viscosity was reached increased as the heating rate increased. This is again attributed to the greater thermal energy input at a given time when a greater heating rate is employed. The time taken to produce peak 2 also decreased as the heating rate increased. Peak 2 viscosity, however, decreased as the heating rate increased. This is again probably due to a decrease in the time available for the formation of amylose-lipid complex Type II before sufficient energy was applied to dissociate the complex.

Figure 5 shows the effect of different starch concentrations on the pasting curve using the standard temperature, time and stirring profile. As expected, peak 1 decreased in area as the concentration of the starch was reduced, and it also appeared slightly later. It is suggested that a lower concentration starch leads to a lower kinetic 


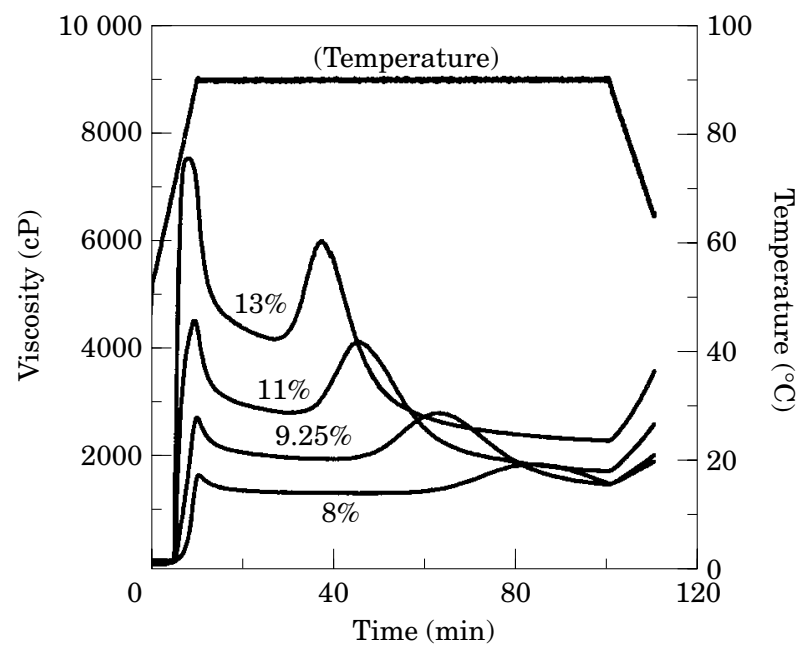

Figure 5 Pasting curves of different concentrations of BDH maize starch.

energy input due to fewer inter-granule and intermolecule interactions and that a decrease in the energy of the system led to a later occurrence in peak viscosity at lower concentrations. Peak 2 also decreased in area and appeared progressively later as the concentration of starch was reduced. Again it is suggested that a lower concentration of starch led to a lower kinetic energy input to the system increasing the time before complex forming and complex dissociation. Even though both peaks decreased in area as the concentration of the starch was reduced, they did not decrease equally (the second peak increased in area relative to the first peak), indicating that the mechanisms responsible for peak 1 and 2 formations are affected differently by the concentration parameter.

Increasing shear by increasing paddle stirring speed from 160 to $500 \mathrm{rev} / \mathrm{min}$ decreased the viscosities and areas of the first and second pasting peaks (data not shown). It is suggested that the greater shear/kinetic energy input to the system discouraged (strong) associations between starch molecules which resulted in a poorer viscosity development. Both the first and second peaks appeared slightly earlier with greater shear/energy input. The area of the second peak relative to the first peak, decreased slightly with an increase in shear. Again, it is suggested that the factors responsible for these two different peaks react differently to additional kinetic energy input.

\section{CONCLUSIONS}

It is concluded that commercial maize starch containing less than $1 \%$ lipid, gives a second viscosity peak at long holding times (between 32 and $45 \mathrm{~min}$ ) at constant temperature $\left(82-92^{\circ} \mathrm{C}\right)$, at starch concentrations of $8-13 \%$ with a wide range of initial heating rates $\left(0.5-10^{\circ} \mathrm{C} / \mathrm{min}\right)$ and shear conditions $(150-500 \mathrm{rev} / \mathrm{min})$. The second pasting peak appears to be due to the formation of starchlipid complexes, possibly the amylose-lipid semicrystalline Type II form.

\section{Acknowledgements}

The authors wish to thank Ms Laurraine Mlotshwa and Mr Kgama Mathiba (CSIR South Africa) for general technical assistance. Mr Leo Odendaal of Rhine Ruhr SA, suppliers of RVA, is also acknowledged for excellent technical support.

\section{REFERENCES}

1. Zobel, H.F. and Stephen, A.M. Starch: structure, analysis, and application. In 'Food Polysaccharides and Their Applications', (A.M. Stephen ed.), Marcel Dekker Inc., New York (1995) pp 19-66.

2. Whistler, R.L. and BeMiller, J.N. Starch. Carbohydrate Chemistry for Food Scientists (R.L. Whistler and J.N. BeMiller, eds), American Association of Cereal Chemists, St Paul (1997) pp 117-151.

3. Donovan, J.W. Phase transition of the starch-water system. Biopolymers 18 (1979) 236-275.

4. Wang, S.S., Chiang, W.C., Zhao, B., Zheng, X.G. and Kim, I.H. Experimental analysis and computer simulation of starch-water interactions during phase transition. Fournal of Food Science 56 (1991) 121-124.

5. Biliaderis, G.G., Maurice, T.J. and Vose, J.R. Starch gelatinisation phenomena studied by differential scanning calorimetry. Fournal of Food Science 45 (1980) 1669-1674.

6. Atwell, W.A., Hood, L.F., Lineback, D.R., VarrianoMarston, E. and Zobel, H.F. The terminology and methodology associated with basic starch phenomena. Cereal Foods World 33 (1988) 306-311.

7. Keetels, C.A.M., Van Vliet, T. and Walstra, P. Gelation and retrogradation of concentrated starch systems: 1 . gelation. Food Hydrocolloids 10 (1996) 343-353.

8. French, D. Organization of starch granules. In 'Starch: Chemistry and Technology' 2nd edition (R.L. Whistler, J.M. BeMiller and E.F. Paschall, eds), Academic Press, London (1984) pp 183-243.

9. Ziegler, G.R., Thompson, D.B. and Casasnovas, J. Dynamic measurement of starch granule swelling during gelatinisation. Cereal Chemistry 70 (1993) 247-261.

10. Hoseney, R.C. Principles of Cereal Science and Technology. Second edition. American Association of Cereal Chemists, St Paul (1994) pp 29-34.

11. Newport Scientific. Operation Manual for the Series 3 Rapid Visco 
Analyser using Thermocline for Windows. Newport Scientific, Warriewood (1995) pp 1-92.

12. Almeida-Dominguez, H.D., Suhendro, E.L. and Rooney, L.W. Factors affecting rapid visco analyser curves for the determination of maize kernel hardness. Fournal of Cereal Science 25 (1997) 93-102.

13. Subramanian, V., Hoseney, R.G. and Bramel-Cox, P. Shear thinning properties of sorghum and corn starches. Cereal Chemistry 71 (1994) 272-275.

14. Gomez, M.H., Lee, J.K., McDonough, C.M., Waniaka, R.D. and Rooney, L.W. Corn starch changes during tortilla and tortilla chip processing. Cereal Chemistry 69 (1992) 275-279.

15. Thiewes, H.J. and Steeneken, P.A.M. Comparison of the Brabender Viscograph and Rapid Visco Analyser 2. Shear conditions. Starch/Stärke 49 (1997) 93-96.

16. International Association for Cereal Science and Technology (ICC). Rapid Pasting Method using the Newport Rapid Visco Analyser. ICG Standard No. 162 (1995) ICG, Vienna.

17. Deffenbaugh, L.B., Lincoln, N.E. and Walker, C.E. Use of the rapid-visco-analyzer to measure starch pasting properties. Part I: Effect of sugars. Starch/Stärke 41 (1989) 461-467.

18. AOAC (Association of Official Analytical Chemists) Offfcial methods of analysis of the Association of Official Analytical Chemists. 13th ed (1980) Washington, DC.

19. Morrison, W.R. Starch lipids and how they relate to starch granule structure and functionality. Cereal Foods World 40 (1995) 437-446.

20. Takahashi, S. and Seib, P.A. Paste and gel properties of prime corn and wheat starches with and without native lipids. Cereal Chemistry 65 (1988) 474-483.

21. Xu, A., Ponte, G. and Chung, O.K. Bread crumb Amylograph studies. II. Cause of unique properties. Cereal Chemistry 69 (1992) 502-507.

22. Kim, W.S. and Seib, P.A. Apparent restriction of starch swelling in cooked noodles by lipids in some commercial wheat flours. Cereal Chemistry 70 (1993) 367-372.

23. Bhattacharya, M. and Corke, H. Selection of desirable starch pasting properties in wheat for use in white salted or yellow alkaline noodles. Cereal Chemistry 73 (1996) 721-728.

24. Melvin, M.A. The effect of extractable lipid on the viscosity characteristics of corn and wheat starches. Journal of the Science of Food and Agriculture 30 (1979) 731738.
25. Eliasson, A.-G., Carlson, T.L.-G., Larsson, K. and Miezis, Y. Some effects of starch lipids on the thermal and rheological properties of wheat starch. Starch/Stärke 33 (1981) 130-134.

26. Ohashi, K., Goshima, G., Kusuda, H. and Tsuge, H. Effect of embraced lipid on the gelatinisation of rice starch. Starch/Stärke 32 (1980) 54-58.

27. Maningat, G.C. and Juliano, B.O. Starch lipids and their effect on rice starch properties. Starch/Stärke 32 (1980) 76-82.

28. Elliasson, A.-C., Finstad, H. and Ljunger, G. A study of starch-lipid interactions for some native and modified starches. Starch/Stärke 40 (1988) 95-100.

29. Osman, E.M. and Dix, M.R. Effects of fats and non-ionic surface-active agents on starch pastes. Cereal Chemistry 37 (1960) 464-475.

30. Miller, B.S., Derby, R.I. and Trimbo, H.B. A pictorial explanation for the increase in viscosity of a heated starchwater suspension. Cereal Chemistry 50 (1973) 271-280.

31. Morrison, W.R. Functionality of lipids in cereal processing. In 'Cereal Science and Technology Impact on a Changing Africa', (J.R.N. Taylor, P.G. Randall and J.H. Viljoen, eds) CSIR (1993) pp 147-162.

32. Morrison, W.R., Tester, R.F., Snape, G.E., Law, R. and Gidley, M.J. Swelling and gelatinisation of cereal starches, IV. Some effects of lipid-complexed amylose and free amylose in waxy and normal barley starches. Cereal Chemistry 70 (1993) 385-390.

33. Morrison, W.R., Tester, R.F., Gidley, M.J. and Karkalas, $\mathrm{J}$. Resistance to acid hydrolysis of lipid-complexed amylose and lipid-free amylose in lintnerized waxy and nonwaxy barley starches. Carbohydrate Research 245 (1993) 289-293.

34. Morrison, W.R., Law, R.V. and Snape, C.E. Evidence for inclusion complexes of lipids with $\mathrm{V}$-amylose in maize, rice and oat starches. Fournal of Cereal Science 18 (1993) $107-112$

35. Raphaelides, S.R. and Karkalas, J. Thermal dissociation of amylose-fatty acid complexes. Carbohydrate Research $\mathbf{1 7 2}$ (1988) 65-82.

36. Biliaderis, G.G. The structure and interactions of starch with food constituents. Canadian Fournal of Physiology and Pharmacology 69 (1991) 60-65.

37. Zobel, H.F. Starch crystal transformations and their industrial importance. Starch/Stärke 40 (1988) 1-7. 